\title{
Open Fracture of Metacarpal Bone
}

National Cancer Institute

\section{Source}

National Cancer Institute. Open Fracture of Metacarpal Bone. NCI Thesaurus. Code C35233.

A traumatic break in one or more of the metacarpal bones that involves a break in the adjacent skin. 